International Journal of Advanced Chemistry, 2(1)(2014) 1-5
International Journal of Advanced Chemistry
Journal home page: $\begin{gathered}\text { www.sciencepubco.com/index.php/IJAC } \\ \text { doi: } 10.14419 / \text { ijac.v2il.1531 } \\ \text { Research Paper }\end{gathered}$

\title{
Biosorption of Ni (II) from aqueous solution using Acer saccharum leaves (ASL) as a potential sorbent
}

\author{
R. Hema Krishna*, W.B. Gilbert \\ Department of chemistry, university of Toronto, Ontario, Canada. M5S $3 H 6$ \\ *Corresponding author E-mail: hkravuri32@gmail.com
}

\begin{abstract}
In this research work Powder of Acer Saccharum Leaves (PASL) were used as a non-conventional, cost-effective sorbent for removal of $\mathrm{Ni}$ (II) from aqueous solutions in batch systems. The sorbent was characterised with respect to surface area, pore volume, etc. It was found that PASL has high specific surface area $(11.99 \mathrm{~m} 2 / \mathrm{g}$ ) and contains Ni (II) binding functional groups (e.g. Hydroxyl and Carboxyl).The biosorbent was characterized by FTIR, SEM and X-ray mapping, and the powder surface area was determined by BET. The optimum biosorption conditions were determined as a function of $\mathrm{pH}$, biomass dosage, contact time, and initial metal ion concentration. The maximum Ni (II) biosorption was obtained at $\mathrm{pH}$ 4.0. The equilibrium data were better fit by the Langmuir isotherm and Freundlich isotherm models. The kinetic studies indicate that the biosorption process of the metal ion Ni (II) has followed well the pseudo-second order, avrami and intraparticle diffusion models.
\end{abstract}

Keywords: Acer Saccharum Leaves (ASL); Adsorption; Adsorption kinetics; adsorption isotherms; Ni (II) ions.

\section{Introduction}

Nickel is well known as a heavy metal pollutant, present in effluents of electroplating industries, smelting, and alloy manufacturing, mining, and refining industries (Denkhaus \& Salnikow 2002, Hema Krishna\& Swamy 2012).According to WHO, the permissible limit of $\mathrm{Ni}(\mathrm{II})$ in drinking water is $0.5 \mathrm{mg} / \mathrm{L}$ (World Health Organization, 2006). The non-biodegradable and bioaccumulation properties of heavy metals may pose serious threats to living organisms, (Liu \& Xu 2007). The hazardous nature of the heavy metals to biological systems has made the governments to impose stringent standards as the disposal. This has prompted many industries to sponsor special studies on the removal of heavy metals. In the process, several methodologies have been adopted but due to operational difficulties, most of them are not in use. Nickel is released into the environment in a large number of processes such as electroplating and steel manufacturing. High nickel concentrations on sandy soils can clearly damage plants and high nickel concentrations in surface waters can diminish the growth rates of algae and microorganisms. Nickel is present in wastewaters from metal processing, steel foundry, motor vehicle and aircraft, leather and chemical industries(Hema Krishna\& Swamy 2011).Humans may be exposed to nickel by breathing air, drinking water, eating food or smoking cigarettes. Skin contact with nickel-contaminated soil or water may also result in nickel exposure. Small amounts of nickel are needed by the human body to produce red blood cells, however, in excessive amounts can become mildly toxic. Short-term overexposure to nickel is not known to cause any health problems, but long-term exposure can cause decreased body weight, heart and liver damage and skin irritation. Nickel may cause dermatitis upon exposure to the skin, and gastrointestinal distress upon ingestion. Studies of human cell cultures have indicated that nickel is a possible carcinogen, creating a need for the cleanup of nickel pollution. So it is very much essential to remove $\mathrm{Ni}$ from soil, industrial wastewater and effluents. The conventional methods which are commonly used for the removal of nickel from the industrial effluents are physico-chemical methods, such as chemical precipitation, chemical oxidation or reduction, electrochemical treatment, evaporative, recovery, filtration, ion exchange, and membrane technologies. These processes may be ineffective or expensive, especially when the heavy metal ions in the contaminated media are high i.e. in order of 1-100 mg dissolved heavy metal ions per liter (Revathi 2005). Secondly the operational problems and the high cost of treatment necessitate research for some newer methods.

In recent years, the exploitation of eco-friendly biosorption technology using inactive and dead biomasses to detoxify metalcontaminated effluents in the aquatic environment is gaining importance day by day (Pino et al.2006 \& Sujatha et al.2013). Moreover; the biosorbents have high specific metal binding ability in complex media in contrast to carbonaceous sorbents which tend to adsorb metal ions in a nonspecific manner. These advantages make biosorbents an economical alternative to commercial activated carbons in the removal of heavy metalpolluted water bodies (Gupta et al.2008).Biosorption is an innovative and developing technology using living or dead biomaterials to reduce toxic heavy metals from aqueous solution. The key advantages of biosorption technology are its effectiveness in reducing the concentration of heavy metal ions to very low levels and the use of inexpensive biosorbent material (Volesky\&Holan1995). Moreover, the lignocellulosic solid wastes generated from agricultural, plantation, and forestry sectors have been highlighted as an alternative potential biosorbent for the removal and recovery of heavy metal ions from the waters and wastewaters (Demirbas 2008, Witek et al.2010).

Acer Saccharum wood has several uses but Acer Saccharum Leaves has no uses till now though it has creates waste man- 
agement problems In an effort to evolve a useful user-friendly, eco-friendly and economical process, the present study was taken up. Hence, this study tries to make use of PASL by evaluating the capability of ASL to adsorb Ni (II) ions from aqueous solutions. The produce biosorbent were characterised by FTIR, BET, SEM and X-ray mapping. Easy availability, economical to use and proven potential for other metals, have been the reasons for selection of this adsorbent Powder of Acer Saccharum Leaves (PASL) were used to adsorb Nickel (II).

\section{Materials and methods}

\subsection{Powder of acer saccharum leaves (PASL)}

Acer Saccharum trees are very famous in Canada. These are the first choice for making syrup as there is more sugar in the sap compared to other species, meaning it will take less sap to produce a gallon of syrup. The sugar Acer Saccharum can tolerate shade better than most large deciduous trees. The Acer Saccharum Leaves were collected from the Local Parks in Toronto and chopped, cleaned and soaked in distilled water for 24 hrs. The soaked pieces of Leaves were sun-dried and powdered and used for all experiments. Size of the particles selected for the study was $0.6 \mathrm{~mm}$.

\subsection{Measurement of $\mathrm{pH}$ of the adsorbent}

Five grams of adsorbent powder was taken into a $1000 \mathrm{ml}$ beaker. To this $150 \mathrm{ml}$ of freshly boiled and cooled water was added and then heated till boiling point. The contents were digested for ten minutes and kept aside for ten minutes. The solution was filtered and $\mathrm{pH}$ was measured. The metal ion solutions for standard solutions and further dilutions were prepared following the procedures described (Jeffery et al.1991).

\subsection{Preparation of metal ion solutions}

The Nickel (II) was estimated using standard methods. AR grade chemicals and double distilled water were used for all the analyses. The concentrations of the metal ions were estimated using UV-visible spectrophotometer.
Standard Nickel Solution: Nickel (II) solution was prepared by using AR Grade nickel ammonium sulphate; $6.7280 \mathrm{~g}$ of nickel ammonium sulphate was taken into a $1000 \mathrm{ml}$ volumetric flask. $5 \mathrm{ml}$ of $1 \% \mathrm{HNO}_{3}$ was added to it immediately. Then the contents were made up to $1000 \mathrm{ml}$ with double distilled water.

\subsection{Analysis of nickel (II)}

Spectrophotometric analysis was adopted to estimate Nickel (II), by using dimethylglyoxime (DMG). Different standard solutions containing less than $100 \mathrm{mg} / \mathrm{l}$ of Nickel (II) were prepared and $2 \mathrm{ml}$ of $20 \% \mathrm{w} / \mathrm{v}$ sodium tartarate solution $10 \mathrm{ml}$ of $4 \% \mathrm{w} / \mathrm{v}$ potassium persulphate $2.5 \mathrm{ml}$ of $5 \mathrm{M}$ sodium hydroxide solutions and $15 \mathrm{ml}$ of $(1+30) \mathrm{HCl}$ solutions were added. Again 0.6 $\mathrm{ml}$ of $1 \%$ DMG solutions were added to this mixture. The contents were made up to $50 \mathrm{ml}$. The absorbance was measured after 30 minutes using UV-visible spectrophotometer at $465 \mathrm{~nm}$. A reagent blank was also prepared for Nickel (II) solution. The amount of Nickel present in the sample was obtained from the calibration curve. The results for a heavy metal concentrations were expressed in $\mathrm{mg} \mathrm{L}^{-1}$ while those of the concentration equilibrium, equilibrium time, and adsorption capacity etc., were compared with the Langmuir and Freundlich isotherms.

\subsection{Analytical methods}

All experiments were carried out at $27{ }^{\circ} \mathrm{C}$ in batch mode. Batch mode was selected because of its simplicity and reliability. The experiments were carried out of taking $50 \mathrm{ml}$ metal ion sample and known amount of the adsorbent in a $100 \mathrm{ml}$ Stoppard conical flask. The flasks were agitated at $160 \mathrm{rpm}$ for predetermined time intervals using a mechanical shaker at room temperature. Control experiments were conducted without absorbent to given correction for metal ion adsorption on the walls of the container. The produced Powder of Acer Saccharum Leaves (PASL) biosorbent was characterised by FTIR, BET, SEM and X-ray mapping. Effects of experimental condition such as $\mathrm{pH}$, biosorbent doses, initial concentration, contact time and particle sizes were conducted in different $\mathrm{pH}(2-9)$, doses $(125 \mathrm{mg} / 50$ $\mathrm{ml})$, initial concentration $(50 \mathrm{mg} / \mathrm{l})$, contact time (0-90 mins) and particle sizes $(0.6 \mathrm{~mm})$. The process of $\mathrm{Ni}$ (II) biosorption showed in Fig.1.

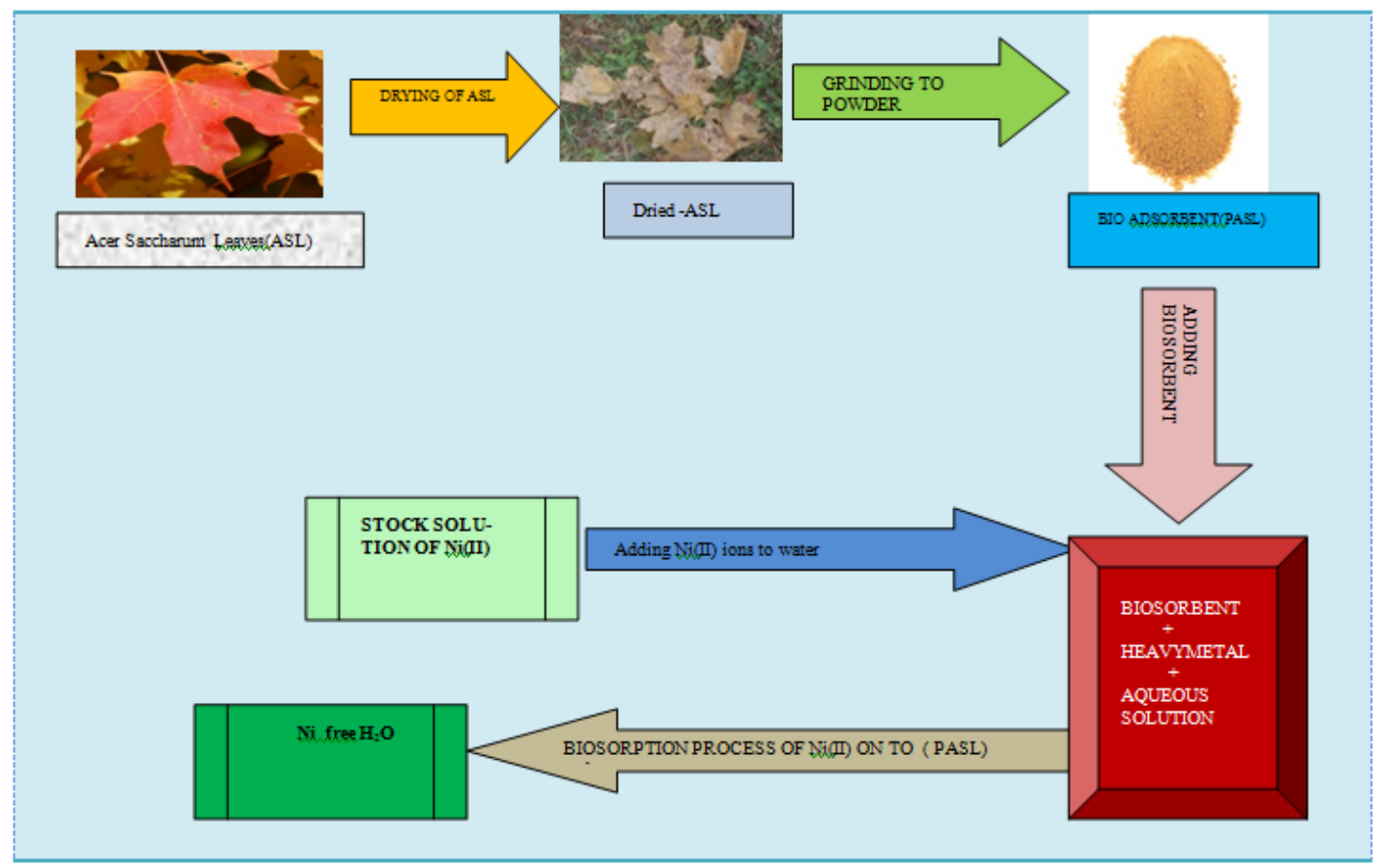

Fig. 1: Biosorption process of Ni (II) onto Powder of Acer Saccharum Leaves (PASL) biosorbent 


\section{Results and discussion}

\subsection{Characterization of biosorbent}

In characterization of biosorbent, BET surface area and total pore volume were $10.94 \mathrm{~m}^{2} / \mathrm{g}$ and $0.02 \mathrm{~cm}^{3} / \mathrm{g}$, respectively. The mean micropore and mesopore sizes of the Powder of Acer Saccharum Leaves (PASL) biosorbent were found to be 8.71 and $41.46 \AA$, respectively and fallen within IUPAC-classification. The surface of Powder of Acer Saccharum Leaves (PASL) biosorbent contains asymmetric pores and irregular particles, which signifies the high internal surface area and could uptake high $\mathrm{Ni}(\mathrm{II})$ ions (Fig.2) After Ni (II) adsorption, the micrographs shows that the pores were filled and dense in structures, which might be filled with adsorbed Ni (II) (Fig.3). The X-ray mapping (Fig.4) showed the presence of adsorbed Ni (II) ions in the surface of biosorbent. The XRD spectrum of Acer Saccharum Leaves (ASL) (Fig.5 and Fig.6) shows the constituents' elements. The major functional groups were $\mathrm{O}-\mathrm{H}$ stretch-free hydroxyl for alcohols/phenols $\left(3624.54 \mathrm{~cm}^{-1}\right), \mathrm{O}-\mathrm{H}$ stretch for carboxylic acids (between 3300$2500 \mathrm{~cm}^{-1}$ ), and $\mathrm{C}-\mathrm{O}$ stretch for alcohols/carboxylic acids/esters/ethers (between 1320-1000 cm-1), which could able to bind with $\mathrm{Ni}$ (II) ions. SEM micrograph 150' (HWOF=600 $\mu \mathrm{m}$ ) of (Fig.2) Acer Saccharum Leaves (ASL) (Fig.3) Acer Saccharum Leaves (ASL) exhausted with Nickel (Fig.4) X-ray mapping of Acer Saccharum Leaves (ASL) exhausted with Nickel (Fig.5) Spectra of maple leaves (Fig.6) Spectra of Acer Saccharum Leaves (ASL) exhausted with Nickel.

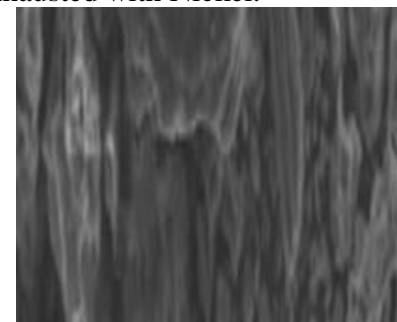

Fig. 2: SEM micrograph $150 x(H W O F=600 \mu m)$ of (a) Acer Saccharum Leaves (ASL).

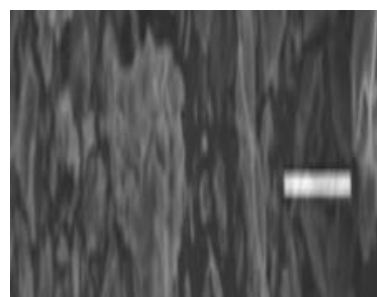

Fig. 3: SEM micrograph $150 \mathrm{x}(\mathrm{HWOF}=600 \mu \mathrm{m})$ of Acer Saccharum Leaves (ASL) exhausted with Nickel.

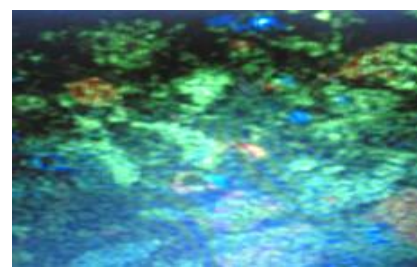

Green-Ni, Blue-Ca, Red-Si

Fig. 4: X-ray mapping of Acer Saccharum Leaves (ASL) exhausted with Nickel

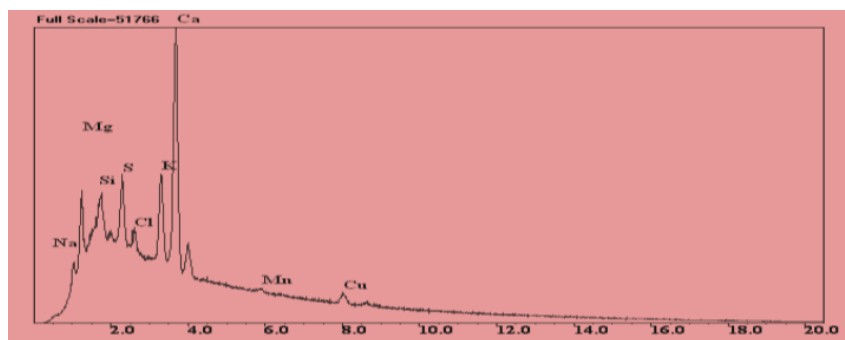

Fig. 5: XRD Spectra of Acer Saccharum Leaves (ASL)

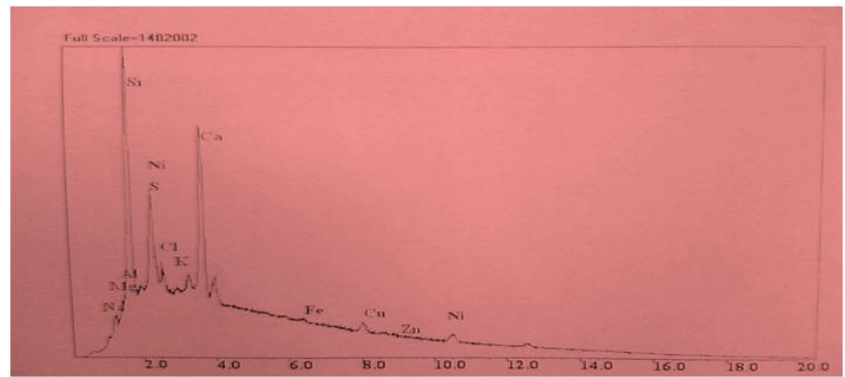

Fig. 6: (e) XRD Spectra of Acer Saccharum Leaves (ASL) exhausted with Nickel

\subsection{Effect of pH on biosorption of Ni (II)}

$\mathrm{pH}$ effects the solubility of metal ions, concentration of counter ions on the functional groups of the adsorbent and the degree of ionization of the adsorbate during reaction .Studies were carried out to obtain optimum $\mathrm{pH}$ for the adsorption of nickel (II) using $125 \mathrm{mg}$ of adsorbent in $50 \mathrm{ml}$ solution of $50 \mathrm{mg} / \mathrm{l}$ of nickel (II) concentration adjusted to different $\mathrm{pH}$ values from 2.0 to 9.0. The solutions after equilibration were centrifuged. The filtrates were tested for $\mathrm{Ni}$ (II) concentrations spectrophotometrically. Fig. 7 shows the effect of $\mathrm{pH}$ on adsorption of $\mathrm{Ni}$ (II) ion. Maximum removal of $95 \%$ was achieved at $\mathrm{pH} 4.0$ and remained almost constant in the $\mathrm{pH}$ range of 7.0 to 9.0. The percentage of adsorption increased with increase in initial $\mathrm{pH}$ and decreased with increase in initial $\mathrm{pH}$ up to 6.0. The adsorption of metal cations depends on the nature of metal ions, adsorbent surface and species of the metals. At lower $\mathrm{pH}$ values Nickel removal was inhibited, possibly because of the competition between hydrogen and nickel ions in the sorption site.With an apparent preponderances of hydrogen ions, it restricts the approach of metal cations as a consequence of the repulsive force . At $\mathrm{pH}>6$ precipitations started and hence, higher $\mathrm{pH}$ was not selected for the present study. Biosorption of nickel $\mathrm{Ni}^{+2}$ was maximum at $\mathrm{pH}=4$, as the $\mathrm{pH}$ exceeded, the biosorption began to decrease. This is possibly due to the precipitations of $\mathrm{Ni}$ (II) ions as a result of hydroxide anions forming nickel hydroxide precipitate. Many authors reported maximum adsorption of $\mathrm{Ni}$ (II) in the $\mathrm{pH}$ range of 3 to 6 . The results obtained for the adsorption of Nickel (II) on the Powder of Acer Saccharum Leaves (PASL) were in good agreement with the results of activated carbon (Saravanan 2001), where $\mathrm{pH}$ was less than 4.5 and adsorption capacity was $\mathrm{pH}$ dependent.

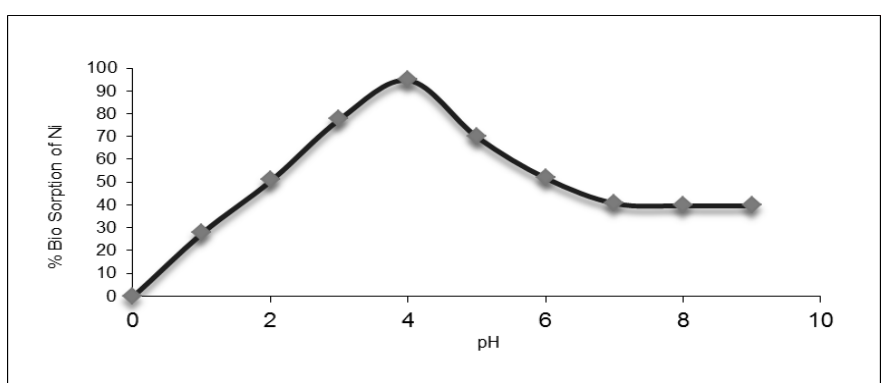

Fig. 7: Effect of $\mathrm{pH}$ on the \% removal of $\mathrm{Ni}$ (II) 


\subsection{Effects of equilibrium time and initial metal ion concentration}

Equilibrium experiments were carried out by agitating $50 \mathrm{ml}$ of different concentrations of $\mathrm{Ni}$ (II) solutions $(50,75$ and $100 \mathrm{mg} / \mathrm{l})$ adjusted to $\mathrm{pH} 4.0$ with $125 \mathrm{mg}$ of adsorbent. After equilibrating for different periods, the solutions were centrifuged and analyzed for Ni (II) content. For maximum removal of Nickel (II) by the adsorbent, the solutions should be equilibrated for $90 \mathrm{~min}$. irrespective of the initial concentration. The amounts of Nickel (II) adsorbed were $20.15 ; 23.87$; and $29.88 \mathrm{mg} / \mathrm{g}$ for initial $\mathrm{Ni}$ (II) concentrations of 50,75 and $100 \mathrm{mg} / \mathrm{l}$, respectively. It was evident from Fig. 8 that for maximum adsorption the solutions were equilibrated for $120 \mathrm{~min}$., the rate of uptake was rapid in the beginning and became slow in the later stages and reached saturation at $90 \mathrm{~min}$. This is due to the fact that the metal ion occupied the sites in a random manner because of maximum availability of sites. As the time, the active sites were blocked and hence the rate decreased. The formation of layer of Ni (II) ions on the outer surface of the adsorbent was inferred, based on the observation that the cures shown in Fig. 2 are single, smoother and continuous. Similar results were reported for Nickel (II) adsorption by (Jebamani \& Saseetharan 2005) for a fruit of Leucaena glauca Benth., was 97.62\% and In case of Powder of Acer Saccharum Leaves per cent removal increased sharply leading to 95.96 removal of Nickel (II), and the per cent removal decreased with an increase in the initial metal ion concentration.

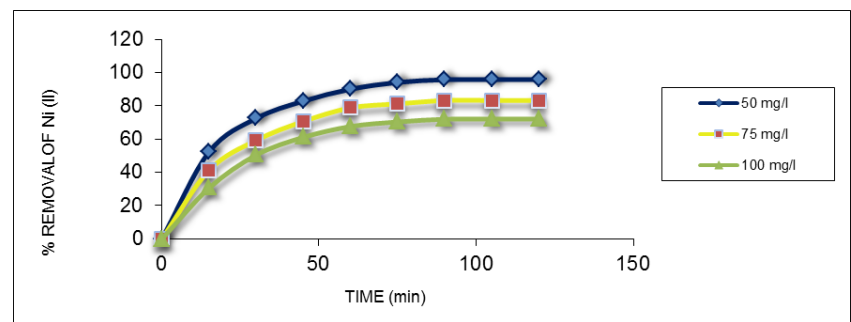

Fig. 8: Effect of time on \% removal of Nickel (II) adsorption

\subsection{Effect of adsorbent dosage}

Studies on the effect of adsorbent dose, different quantities of the adsorbent ranging from 25 to $150 \mathrm{mg}$ were used. Known quantities of adsorbent were added to $50 \mathrm{ml}$ of $\mathrm{Ni}$ (II) solutions of concentration $50 \mathrm{mg} / \mathrm{l}$ and the solutions were agitated for $90 \mathrm{~min}$. After equilibrium time, the solutions were centrifuged and analyzed for Nickel (II) Content. It is evident from the Fig.9 that the increase of adsorbent dose, the percent removal of $\mathrm{Ni}$ (II) also increased and a complete 100 percent removal was achieved with a dose of $150 \mathrm{mg} / 50 \mathrm{ml}$. This was attributed to an increase in number of binding sites with increased dosage (Viraraghavan \& Dronam Raju1993).

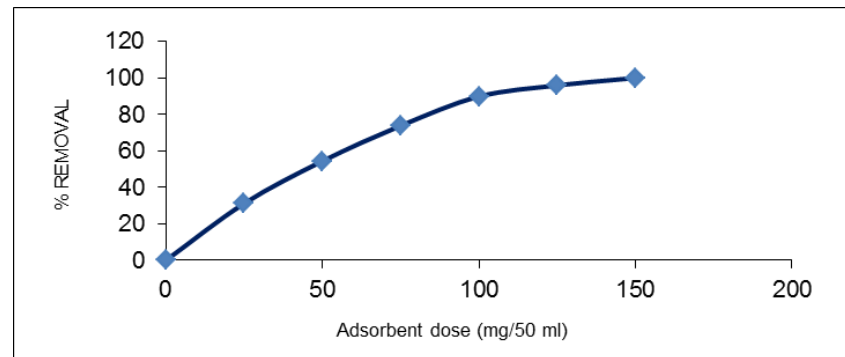

Fig. 9: Effect of adsorbent dose on the \%removal of Ni (II).

\subsection{Adsorption isotherms}

The Langmuir constants $\mathrm{Q}_{0}$ and $\mathrm{b}$ calculated from the slope and intercept of the Fig. 10 were $31.85 \mathrm{mg} / \mathrm{l}$ and $0.6192 \mathrm{mg} / 1 \mathrm{respec}-$ tively. Comparison of these values with the literature data indicates that Qo obtained for this adsorbent is less than the Qo obtained by adsorption on activated carbon prepared from biomass by (Kadirvelu \& Subburam 2003).

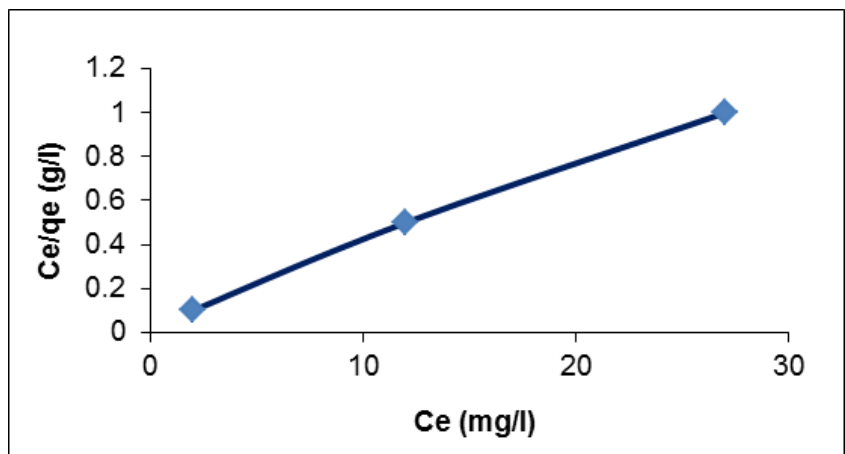

Fig. 10: Langmuir isotherm showing initial concentration vs. equilibrium concentration

The adsorption data also obeyed Freundlich adsorption isotherm; it is evident from the Fig.11 where the plots are linear. Freundlich constants $\mathrm{K}_{\mathrm{f}}$ and $\mathrm{n}$ calculated are 29.02 are 3.56 respectively. Freundlich constant reported was 39.8 by adsorption of silk cotton hull activated carbon studied by (Valli et al.2006). According to (Mckay et al.1982, Hema Krishna \& Swamy 2013) the value of $n$ between 2 and 10 indicated good adsorption. The calculated value of $\mathrm{n}$ for the adsorption of nickel was 3.56, inferring very good efficiency for Nickel (II) adsorption by powder of acer saccharum leaves.

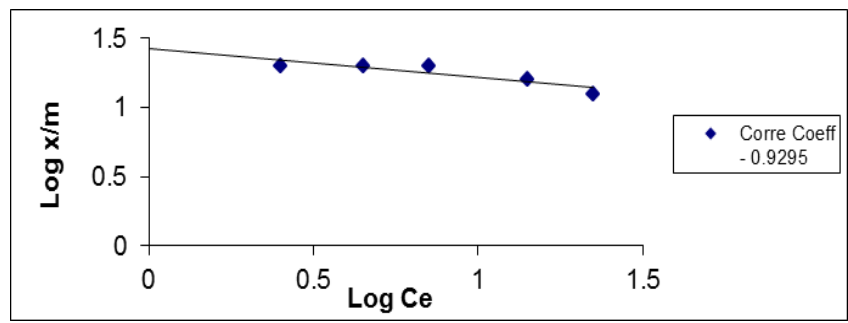

Fig. 11: Freundlich adsorption isotherm for adsorption of $\mathrm{Ni}$ (II)

\subsection{Bio sorption kinetics}

To know the kinetics of Ni (II) ions adsorption process kinetics experiments were conducted at 50, 75 and $100 \mathrm{mg} / \mathrm{l} \mathrm{Ni}$ (II) concentration for $90 \mathrm{~min}$ at $\mathrm{pH} 4.0$ and room temperature. Experimental data were fitted with pseudo-first-order, pseudo secondorder, Avrami and Intraparticle diffusion models shown in Table 1. Among the models, pseudo-second-order and Avrami models poses good agreement with experimental data and showed similar prediction with experimental values of equilibrium adsorption capacity. Intraparticle diffusion model also indicates that the adsorption process was rate controlling and multistep (nAV>1).

Table 1: Kinetic models Parameters

\begin{tabular}{lllll}
\hline $\begin{array}{l}\text { Kinetic models Parame- } \\
\text { ters Adsorption }\end{array}$ & Parameters & $\begin{array}{l}\text { Adsorption } \\
\text { Nickel(II) } \\
(\mathrm{mg} / \mathrm{l})\end{array}$ & & \\
& & 50 & 75 & 100 \\
\hline Experimental & $\mathrm{qe}(\mathrm{mg} / \mathrm{g})$ & 1.894 & 9.920 & 19.154 \\
& $\mathrm{qe}(\mathrm{mg} / \mathrm{g})$ & 2.044 & 9.987 & 19.112 \\
& $\mathrm{k} 1(\mathrm{l} / \mathrm{h})$ & 1.000 & 1.000 & 1.000 \\
& $\mathrm{R} 2$ & 0.924 & 0.930 & 0.977 \\
1. Pseudo-1 st-order & $\mathrm{NSD}$ & 10.886 & 10.616 & 5.546 \\
$q_{t}=q_{e}+q e^{-(k t)}{ }_{1}$ & $\mathrm{ARE}$ & 1.1814 & 1.190 & 0.814 \\
& & & & \\
& $\mathrm{qe}(\mathrm{g} / \mathrm{mg} \cdot \mathrm{min})$ & 2.017 & 9.650 & 19.140 \\
2. Psedo-2nd order & $\mathrm{k} 2(1 / \mathrm{h})$ & 3.000 & 2.000 & 0.177 \\
\hline
\end{tabular}




\begin{tabular}{cllll}
\hline$q_{t}=k_{2} q_{e}^{2} t$ & $\mathrm{R}^{2}$ & 0.998 & 0.999 & 1.000 \\
$-\left(1+k_{2} q_{e} t\right)$ & $\mathrm{h}=\mathrm{k}_{2} \mathrm{q}_{\mathrm{e}}{ }^{2}$ & 12.526 & 191.11 & 67.062 \\
& & 4.287 & 0.595 & 0.557 \\
& $\mathrm{NSD}$ & 0.013 & -0.004 & -0.007 \\
& $\mathrm{ARE}$ & & & \\
& & & & \\
& $\mathrm{qe}(\mathrm{mg} / \mathrm{g})$ & 1.971 & 9.798 & 18.948 \\
3. Avrami & $\mathrm{KAV}(/ \mathrm{min})$ & 2.798 & 2.161 & 0.809 \\
& $\mathrm{nAV}$ & 2.764 & 2.161 & 1.857 \\
$q_{t}=q_{e}\left(1-e^{(-K A V t) n A V}\right)$ & $\mathrm{R} 2$ & 1.000 & 1.000 & 0.999 \\
& $\mathrm{NSD}$ & 0.601 & 0.661 & 1.405 \\
& $\mathrm{ARE}$ & -0.009 & -0.004 & -0.018 \\
& $\mathrm{kp}(\mathrm{mg} / \mathrm{g} / \mathrm{min})$ & 2.098 & 1.844 & 16.938 \\
4. Intraparticle diffusion & $\mathrm{C}$ & -0.408 & -0.251 & -0.376 \\
& $\mathrm{R} 2$ & 0.987 & 0.785 & 0.987 \\
$q_{t}=\mathrm{K}_{\mathrm{p}} \mathrm{t}^{0.5+\mathrm{c}}$ & $\mathrm{NSD}$ & 2.248 & 53.808 & 5.447 \\
& $\mathrm{ARE}$ & -1.839 & 47.933 & -0.354 \\
& & & &
\end{tabular}

\section{Conclusion}

The experiments conducted on the biosorption of $\mathrm{Ni}$ (II) from aqueous solution using acer saccharum leaves (ASL) as a potential sorbent revealed that the biosorbent has high potential of removing $\mathrm{Ni}$ (II) from the aqueous solution through biosorption mechanism. Certain important physical and chemical characteristics of the biosorption process were analyzed and reported in this paper. The following significant observations were made during the study:

1) Powder of Acer Saccharum Leaves (PASL) were used as a non-conventional, cost-effective sorbent for removal of $\mathrm{Ni}$ (II) from aqueous solutions in batch systems. The major functional groups in the sorbent were $\mathrm{O}-\mathrm{H}$ stretch-free hydroxyl for alcohols/phenols (3624.54 cm-1), O-H stretch for carboxylic acids (between 3300-2500 cm-1), and C-O stretch for alcohols/carboxylic acids/esters/ethers (between 1320-1000 cm-1), which could able to bind with $\mathrm{Ni}$ (II) ions.

2) The maximum $\mathrm{Ni}$ (II) biosorption was obtained at $\mathrm{pH}$ 4.0. In case of Powder of Acer Saccharum Leaves per cent removal increased sharply leading to 95.96 removal of Nickel.

3) The equilibrium data were better fit by the Langmuir isotherm and Freundlich isotherm models.

4) The kinetic studies indicate that the biosorption process of the metal ion $\mathrm{Ni}$ (II) has followed well the pseudo-second order, avrami and intraparticle diffusion models.

5) Extensive research work was in progress in our laboratory regarding biosorption process in the direction of removal of heavy metals from industrial wastewater using low cost sorbents by Sorption Technology.

\section{Acknowledgement}

The author thankful to Environment Canada and Department of chemistry, University of Toronto for providing financial assistance and laboratory facilities to carry out the current study. The author also gratefully acknowledge all the members of the Research Group and co-faculty members of the Department of chemistry, University of Toronto, for their useful remarks, suggestions and moral support to complete this manuscript.

\section{References}

[1] Demirbas A, Heavy metal adsorption onto agro-based waste materials: A review, Journal of Hazardous Materials, 157 (2008) 220-229.

[2] Denkhaus E, Salnikow K, Nickel essentiality, toxicity, and carcinogenicity, Critical Reviews in Oncology/Hematology 42(2002)35-56.

[3] Gupta VK, Rastogi A, Biosorption of lead (II) from aqueous solutions by non-living algal biomass Oedogonium sp. and Nostoc sp. a comparative study. Colloids and Surfaces. 64(2008)70-178.

[4] Hema Krishna R , Comparative Studies of isotherm and kinetics on the adsorption of $\mathrm{Cr}(\mathrm{VI})$ and Ni (II) from Aqueous Solutions by Pow- der of Mosambi Fruit Peelings, International Research Journal of Pure and Applied Chemistry 4 (2013)26-45.

[5] Hema Krishna R, Swamy A.V.V.S, Physico-chemical key parameters, Langmuir and Freundlich isotherm and Lagergren rate constant studies on the removal of divalent nickel from the aqueous solutions onto powder of calcined brick. International Journal of Engineering Research and Development 4 (2012) 29-38.

[6] Hema Krishna R, Swamy A.V.V.S, Studies on the removal of Ni (II) from aqueous solutions using powder of mosambi fruit peelings as a low cost sorbent. Chemical Sciences Journal, CSJ-31(2011)1-13. doi: 10.4172/2150-3494.1000022

[7] Jebamani M.I.S, Saseetharan M.K, Adsorption batch studies on activated carbon in removing nickel and lead. International Journal Environmental Protection, 25(2005) 809-815.

[8] Jeffery GH, Bassett J , Mendnam J , Vogel's Text Book of Quantitative Chemical Analysis, ELBSLongman, London, (1991)207-208.

[9] Kadirvelu K, and Subburam V, Activated carbon prepared from biomass as an adsorbent for the removal of $\mathrm{Ni}$ (II) from aqueous solution. International Journal Environmental Protection 23(2003)1343-1350.

[10]Liu $\mathrm{Y}, \mathrm{Xu} \mathrm{H}$, Equilibrium, thermodynamics and mechanisms of $\mathrm{Ni}^{+}$ biosorption by aerobic granules, Biochemical Engineering Journal 35(2007)174-182.

[11]Mckay G, Blair H.S, Gardner J.K,Adsorption of dyes on chitin equilibrium studies. Journal of Applied Polymer Science, 27(1982) $3043-$ 3057.

[12]Pino GH,.De Mesquita LMS,Torem ML, Pinto GAS, Biosorption of heavy metals by powder of green coconut shell. Separation Science and Technology, 41(2006) 3141-3153.

[13]Revathi M, Removal of nickel ions from industrial plating effluents using activated alumina as adsorbent. Journal of Environmental Engineering 47(2005)1-6.

[14] Saravanan RT, Sundararajan S,Sivamurthy Reddy, Chemically modified low cost treatment for heavy metal effluent management, Environmental Management and Health 12(2) (2001) 215-224.

[15] Sujatha P, Kalarani V, Naresh Kumar B, Effective Biosorption of Nickel (II) from Aqueous Solutions Using Trichoderma viride. Journal of Chemistry (2013)1-7.doi.org/10.1155/2013/716098.

[16] Valli S, Madhavakrishnan S.M, Kadirvelu K, Satishkumar, Mohanraj, S.Pattabhi R, Removal of Ni (II) from aqueous solution using silk cotton hull activated carbon. International Journal Environmental Protection26 (2006) 7-53.

[17]Viraraghavan T. Dronam Raju M.M, Removal of copper, nickel and zinc from waste water by adsorption using peat". Journal of Environmental Science and Health. 28(1993)1261-1276.

[18] Volesky B, Holan Z, Biosorption of heavy metals, Biotechnol Progr, 11(1995) 235-250.

[19]Witek-Krowiak A, Krysiak M, Modelski S, Eckert K, Kloczkowski P, Biosorption of cationic dyes from aqueous solutions with maple leaves, Chemical and Process Engineering Selected full texts, 31(2010)825-837.

[20]World Health Organization, Guidelines for Drinking-Water Quality, Incorporating First addendum to Third Edition, vol. 1, World Health Organization, Geneva, Switzerland, 3rd edition, (2006). 